\title{
Outcome of segmental prosthesis reconstruction for diaphyseal bone tumors: a multi-center retrospective study
}

\author{
Kai Zheng ${ }^{1}$, Xiu-chun $\mathrm{Yu}^{1 *}{ }^{*}$, Yong-cheng $\mathrm{Hu}^{2}$, Zeng-wu Shao ${ }^{3}$, Ming $\mathrm{Xu}^{1}$, Bai-chuan Wang ${ }^{3}$ and Feng Wang ${ }^{2}$
}

\begin{abstract}
Background: The optimal reconstructive method after diaphyseal malignant bone tumor resection remains controversial. This multicenter clinical study was designed to investigate the clinical value and complications of segmental prosthesis in the repair of diaphyseal defects.

Methods: We present 49 patients from three clinical centers treated with wide resection for primary or metastatic bone tumors involving the diaphysis of the femur, tibia, humerus, or ulna, followed by reconstruction using a modular intramedullary segmental prosthesis.

Results: Enrolled patients included 23 men and 26 women with a mean age of 63.3 years. Of these, seven patients had primary bone tumors and 42 patients had metastatic lesions. At the mean follow-up of 13.7 months, 17 patients were alive, 31 patients were deceased due to tumor progression, and one patient was dead of another reason. There were eight nononcologic complications (two with radial nerve injury, three with delayed incision healing, two with aseptic loosening in the proximal humerus prosthetic stem and one with structural failure) and three oncologic complications (three with primary tumor recurrence) among all patients. The incidence of complications in primary tumor patients (4/7, $57.1 \%)$ was higher than that in patients with metastatic tumors $(7 / 42,16.7 \%)(p=0.036)$. Aseptic loosening and mechanical complications were not common for patients with primary tumors, although the reconstruction length difference was statistically significant $(p=0.023)$. No statistically significant differences were observed in limb function, while the mean musculoskeletal tumor society score was 21.2 in femora, 19.6 in humeri, and 17.8 in tibiae $(p=0.134)$.
\end{abstract}

Conclusions: Segmental prostheses represent an optional method for the reconstruction of diaphyseal defects in patients with limited life expectancy. Segmental prostheses in the humerus experienced more complications than those used to treat lesions in the femur.

Keywords: Segmental prostheses, Diaphysis tumors, Diaphyseal defects, Bone reconstruction, Retrospective study, Pathological fractures, Assistant plate

\section{Background}

The reconstruction of diaphyseal defects following malignant tumor resection has long been a challenge. However, the optimal choice of reconstructive method remains controversial [1]. Alternative reconstruction methods include autografts $[2,3]$, allografts $[4,5]$, bone transport [6], inactivated bone replantation $[7,8]$, and segmental prostheses [9-12]. Autografts with fibula or ilium have good bone

\footnotetext{
* Correspondence: 13969132190@163.com

1Department of Orthopedics, The 960th Hospital of the PLA Joint Logistice Support Force (previous name: General Hospital of Jinan Military Command), No. 25 Shifan Road, Jinan 250031, China

Full list of author information is available at the end of the article
}

tissue compatibility, playing an important role in diaphyseal reconstruction, but are limited by autologous bone sources and cause bone defect at the source $[1,3]$. Allograft reconstruction can be used in large diaphyseal defects with good matching, but its disadvantages include the risk of disease transfer to the host, allograft rejection, long recovery, nonunion, allograft fracture, and early infection $[1,4]$. Bone transport can achieve good biological reconstruction after successful operations. However, a long period of transport time and limb bearing limitation, external fixation pin tract infection, and skin and soft tissue cutting injuries are common complications [6]. Inactivated-bone replantation has

(c) The Author(s). 2019 Open Access This article is distributed under the terms of the Creative Commons Attribution 4.0 International License (http://creativecommons.org/licenses/by/4.0/), which permits unrestricted use, distribution, and reproduction in any medium, provided you give appropriate credit to the original author(s) and the source, provide a link to the Creative Commons license, and indicate if changes were made. The Creative Commons Public Domain Dedication waiver (http://creativecommons.org/publicdomain/zero/1.0/) applies to the data made available in this article, unless otherwise stated. 
good shape matching, but the disadvantages include bone strength decrease and the risk of tumor recurrence $[7,8]$. The advantages of segmental prosthesis reconstruction include early mobilization, simple operation, short hospital stay and the ability to tolerate chemotherapy and radiotherapy after incision healing. However, mechanical failure and aseptic loosening of the prosthesis are important concerns $[9,13,14]$. Compared to other reconstruction methods, the available literature on segmental prostheses is scarce and the clinical effects of segmental prostheses are not clear.

This study was performed to better understand the outcomes and complications of segmental prosthesis reconstruction performed after diaphyseal tumor resection.

\section{Methods}

\section{Patients}

We retrospectively studied the medical records of patients treated between 2010 and 2017 at three musculoskeletal oncology centers in China. Inclusion criteria were patients with segmental bone loss from primary malignant or metastatic tumor resection with sparing of the joint, deemed unsuitable for biologic reconstruction, and who were surgically treated with a modular intercalary segmental prosthesis in the diaphysis of the ulna, humerus, tibia, or femur.

We described the surgical indications and patient prognosis, focusing on postoperative limb function, causes of surgical complications, and treatments reducing prosthesis failure. All patients were included at the postoperative evaluation until death or the latest examination for the purpose of this study (Table 1). Adjuvant treatments, including chemotherapy, radiotherapy and targeted therapy, were administered in some patients according to the pathological type of their tumor.

Preoperative X-ray, CT scan, MR imaging and ECT for all bones were performed. The tumor pathological types were confirmed by pathological examination of tumor biopsies or resected specimens. Patients with primary diaphyseal tumors without pathological fracture were considered for segmental prosthesis reconstruction if their bone strength evaluation score was higher than 8 points [15]. Patients with metastatic diaphyseal tumors without pathological fracture accepted segmental prosthesis reconstruction if the obtained Mirel's score [16] was more than 9 points. All patients with pathological diaphyseal fractures accepted segmental prosthesis reconstruction if the patient's physical condition could tolerate surgical treatment.

All patients underwent en bloc resection of tumors, followed by reconstruction with second-generation modular intramedullary segmental prostheses characterized by a lap joint [17] (Fig. 1). All prosthesis intramedullary stems were fixed with bone cement and an assistant plate was used when the intramedullary stem was shorter than 5 $\mathrm{cm}$. The biomechanical analysis showed that the use of assistant plate improved the rigidity of anti-tension and anti-torsion, and diminished the risk of prosthetic loosening and dislocation [18]. All patients in this series were followed-up regularly and underwent postoperative limb function evaluation. The regular follow-up was performed in the outpatient department. Follow-up records included patients' feeling, proprioception, imaging reexamination, and limb function evaluation, which was quantified by the Musculoskeletal Tumor Society (MSTS) score [19].

\section{Statistical analysis}

All patient analysis was conducted with regard to survivorship, complications, site of complication, and functional outcomes. First, the following descriptive statistics were calculated: frequency, percent, mean and standard deviation. Thereafter, comparisons were performed using Student's t-test for continuous variables and Pearson's Chi square test/Fisher's exact test for categorical variables. The level of statistical significance was set at $p<$ 0.05 . All statistical analyses were performed using the GraphPad Prism Software (Version 5; GraphPad Software, Inc., La Jolla, CA, USA).

\section{Results}

There were 49 patients enrolled in the study, including 23 males and 26 females, with a mean age of 63.3 years (range, $13-83$ years). Modular intramedullary segmental prosthesis reconstruction was performed in all patients, which included 30 (61.2\%) femora, 13 (26.5\%) humeri, five (10.2\%) tibiae, and one (2.0\%) ulna (Fig. 2). Seven patients (14.3\%) with a mean age of 48.9 years (range, $13-83$ years) had primary tumors and $42(85.7 \%)$ patients with a mean age of 65.7 years (range, $45-82$ years) had metastatic lesions. Of the 49 cases, 37 cases had a pathological fracture of the surgical site. The histological diagnosis, patient age, surgical sites, preoperative and surgical details, follow-up, complications, and MSTS scores for each patient are reported in Table 1 . The mean defect size was $92.4 \mathrm{~mm}$ (humerus = $80.0 \mathrm{~cm}$, tibia $=98.0 \mathrm{~mm}$, femur $=97.3 \mathrm{~mm}$ ). The mean reconstruction length was $112.9 \mathrm{~mm}$ for primary bone tumor and $89.0 \mathrm{~mm}$ for diaphyseal metastasis. Twelve patients accepted assistant plate fixation of the prothesis, including 5 for the humerus, 6 for the femur, and one for the tibia (Fig. 3). The average duration of follow-up was 16.0 months (range, 3-38 months) for patients with primary bone tumors and 13.2 months (range, 3-79 months) for those with diaphyseal metastasis. At latest follow-up, 31 (63.3\%) of patients died of disease, one patient $(2.0 \%)$ died of other causes, four (8.2\%) showed no evidence of disease, and 13 (26.5\%) were alive with disease.

Overall, 11 patients (22.4\%) developed complications in this series (Table 2). The complications were divided into four classes, according to the five modes of failure for prosthetics proposed by Henderson et al. [20]. Of 
Table 1 presents data of 49 patients; it is a case series study

\begin{tabular}{|c|c|c|c|c|c|c|c|c|c|}
\hline No. & $\begin{array}{l}\text { Age range } \\
\text { (years) }\end{array}$ & Location & Diagnosis & $\begin{array}{l}\text { Pathological fracture } \\
\text { (yes/no) }\end{array}$ & $\begin{array}{l}\text { Resection } \\
\text { length (mm) }\end{array}$ & $\begin{array}{l}\text { Plate used } \\
\text { (yes/no) }\end{array}$ & $\begin{array}{l}\text { Followup } \\
\text { (months) }\end{array}$ & Complications & $\begin{array}{l}\text { MSTS } \\
\text { score }\end{array}$ \\
\hline 1 & $>80$ & Ulna & $\begin{array}{l}\text { Undifferentiated } \\
\text { sarcoma }\end{array}$ & Yes & 60 & No & 38 & None & 28 \\
\hline 2 & $41-50$ & Humerus & Prostate cancer & Yes & 80 & Yes & 16 & None & 21 \\
\hline 3 & $61-70$ & Humerus & Rectal cancer & Yes & 90 & Yes & 6 & $\begin{array}{l}\text { Radial nerve } \\
\text { injuries }\end{array}$ & 15 \\
\hline 4 & $61-70$ & Humerus & Lung cancer & No & 90 & No & 10 & $\begin{array}{l}\text { Aseptic loosening } \\
\text { loosening } 4 \mathrm{~mm}\end{array}$ & 20 \\
\hline 5 & $71-80$ & Humerus & $\begin{array}{l}\text { Multiple } \\
\text { myeseloma }\end{array}$ & Yes & 90 & Yes & 3 & None & 18 \\
\hline 6 & $51-60$ & Humerus & Lung cancer & Yes & 80 & Yes & 3 & None & 17 \\
\hline 7 & $51-60$ & Humerus & Lung cancer & No & 80 & No & 8 & None & 19 \\
\hline 8 & $>80$ & Humerus & Liver cancer & Yes & 80 & No & 4 & None & 16 \\
\hline 9 & $61-70$ & Humerus & Breast cancer & Yes & 60 & No & 17 & None & 23 \\
\hline 10 & $51-60$ & Humerus & Lung cancer & No & 80 & No & 13 & None & 22 \\
\hline 11 & $61-70$ & Humerus & $\begin{array}{l}\text { Multiple } \\
\text { myeseloma }\end{array}$ & Yes & 85 & No & 26 & Aseptic loosening & 25 \\
\hline 12 & $71-80$ & Humerus & Lung cancer & No & 75 & No & 22 & None & 22 \\
\hline 13 & $41-50$ & Humerus & Prostate cancer & Yes & 80 & Yes & 12 & None & 22 \\
\hline 14 & $61-70$ & Humerus & Rectal cancer & Yes & 90 & No & 6 & $\begin{array}{l}\text { Radial nerve } \\
\text { injuries }\end{array}$ & 15 \\
\hline 15 & $51-60$ & Femur & Lung cancer & Yes & 80 & No & 4 & None & 22 \\
\hline 16 & $71-80$ & Femur & Rectal cancer & Yes & 100 & No & 3 & None & 19 \\
\hline 17 & $51-60$ & Femur & Liver cancer & Yes & 110 & No & 4 & None & 19 \\
\hline 18 & $31-40$ & Femur & Osteosarcoma & Yes & 110 & No & 25 & Tumor recurrence & 16 \\
\hline 19 & $51-60$ & Femur & Breast cancer & Yes & 160 & Yes & 36 & None & 27 \\
\hline 20 & $71-80$ & Femur & Rectal cancer & Yes & 90 & No & 8 & None & 22 \\
\hline 21 & $61-70$ & Femur & Renal cancer & Yes & 80 & No & 9 & None & 24 \\
\hline 22 & $61-70$ & Femur & Lung cancer & Yes & 120 & No & 10 & None & 26 \\
\hline 23 & $51-60$ & Femur & Renal cancer & Yes & 80 & No & 14 & None & 22 \\
\hline 24 & $61-70$ & Femur & Breast cancer & Yes & 80 & Yes & 7 & None & 20 \\
\hline 25 & $61-70$ & Femur & Liver cancer & Yes & 80 & No & 4 & None & 19 \\
\hline 26 & $61-70$ & Femur & Lung cancer & Yes & 100 & No & 9 & None & 21 \\
\hline 27 & $61-70$ & Femur & Lung cancer & Yes & 80 & No & 3 & Angulation & 21 \\
\hline 28 & $71-80$ & Femur & $\begin{array}{l}\text { Multiple } \\
\text { myeseloma }\end{array}$ & Yes & 120 & No & 10 & None & 25 \\
\hline 29 & $71-80$ & Femur & $\begin{array}{l}\text { Unknown source } \\
\text { cancer }\end{array}$ & Yes & 70 & Yes & 3 & $\begin{array}{l}\text { Incision delayesed } \\
\text { healing }\end{array}$ & 15 \\
\hline 30 & $71-80$ & Femur & $\begin{array}{l}\text { Non-Hodgkin } \\
\text { lyesmphoma }\end{array}$ & Yes & 150 & Yes & 10 & None & 19 \\
\hline 31 & $71-80$ & Femur & Lung cancer & Yes & 90 & Yes & 8 & None & 16 \\
\hline 32 & $51-60$ & Femur & Lung cancer & No & 80 & No & 12 & None & 22 \\
\hline 33 & $61-70$ & Femur & Lung cancer & No & 100 & No & 7 & None & 18 \\
\hline 34 & $51-60$ & Femur & Lung cancer & No & 120 & No & 15 & None & 27 \\
\hline 35 & $>80$ & Femur & Renal cancer & Yes & 80 & No & 79 & None & 28 \\
\hline 36 & $71-80$ & Femur & Renal cancer & Yes & 100 & No & 38 & None & 27 \\
\hline 37 & $51-60$ & Femur & Breast cancer & Yes & 60 & No & 3 & None & 19 \\
\hline 38 & $41-50$ & Femur & Lung cancer & No & 120 & No & 14 & None & 24 \\
\hline
\end{tabular}


Table 1 presents data of 49 patients; it is a case series study (Continued)

\begin{tabular}{|c|c|c|c|c|c|c|c|c|c|}
\hline No. & $\begin{array}{l}\text { Age range } \\
\text { (years) }\end{array}$ & Location & Diagnosis & $\begin{array}{l}\text { Pathological fracture } \\
\text { (yes/no) }\end{array}$ & $\begin{array}{l}\text { Resection } \\
\text { length (mm) }\end{array}$ & $\begin{array}{l}\text { Plate used } \\
\text { (yes/no) }\end{array}$ & $\begin{array}{l}\text { Followup } \\
\text { (months) }\end{array}$ & Complications & $\begin{array}{l}\text { MSTS } \\
\text { score }\end{array}$ \\
\hline 39 & $10-20$ & Femur & Osteosarcoma & Yes & 190 & No & 3 & None & 18 \\
\hline 40 & $71-80$ & Femur & Breast cancer & Yes & 60 & No & 6 & None & 19 \\
\hline 41 & $71-80$ & Femur & Renal cancer & Yes & 80 & No & 3 & None & 16 \\
\hline 42 & $51-60$ & Femur & Lung cancer & Yes & 80 & No & 4 & None & 17 \\
\hline 43 & $71-80$ & Femur & $\begin{array}{l}\text { Unknown source } \\
\text { cancer }\end{array}$ & Yes & 70 & Yes & 23 & $\begin{array}{l}\text { Incision delayesed } \\
\text { healing }\end{array}$ & 20 \\
\hline 44 & $71-80$ & Femur & $\begin{array}{l}\text { Non-Hodgkin } \\
\text { lyesmphoma }\end{array}$ & Yes & 80 & No & 46 & None & 27 \\
\hline 45 & $41-50$ & Tibia & $\begin{array}{l}\text { Langerhans cell } \\
\text { sarcoma }\end{array}$ & No & 100 & No & 21 & Tumor recurrence & 10 \\
\hline 46 & $61-70$ & Tibia & $\begin{array}{l}\text { Undifferentiated } \\
\text { sarcoma }\end{array}$ & No & 100 & No & 13 & $\begin{array}{l}\text { Incision delayesed } \\
\text { healing }\end{array}$ & 18 \\
\hline 47 & $61-70$ & Tibia & $\begin{array}{l}\text { Unknown source } \\
\text { cancer }\end{array}$ & Yes & 60 & Yes & 21 & None & 22 \\
\hline 48 & $41-50$ & Tibia & $\begin{array}{l}\text { Soft tissue } \\
\text { sarcoma }\end{array}$ & No & 100 & No & 7 & Tumor recurrence & 20 \\
\hline 49 & $51-60$ & Tibia & Osteosarcoma & No & 130 & No & 7 & None & 19 \\
\hline
\end{tabular}

these 11 patients, five (10.2\%; patients $3,13,29,43$, and 26) had type I failure (soft tissue failure), which included radial nerve injury (patients 3 and 13) and delayed incision healing (patients 29, 43, and 26), two cases (4.1\%; patients 4 and 11) had type II failure (aseptic loosening), which occurred at the proximal humerus prosthetic stem, one case (2.0\%; patient 27 ) had type III failure (structural failure), which occurred between the prosthetic axis and the biologic axis, and three cases (6.1\%; patients $18,45,48$ ) had type $\mathrm{V}$ failure (tumor progression), which occurred in three of the patients with primary bone tumor. Two of the 13 patients who accepted humeral prosthetic reconstruction presented postoperative radial nerve paralysis. Although nerve rehabilitation

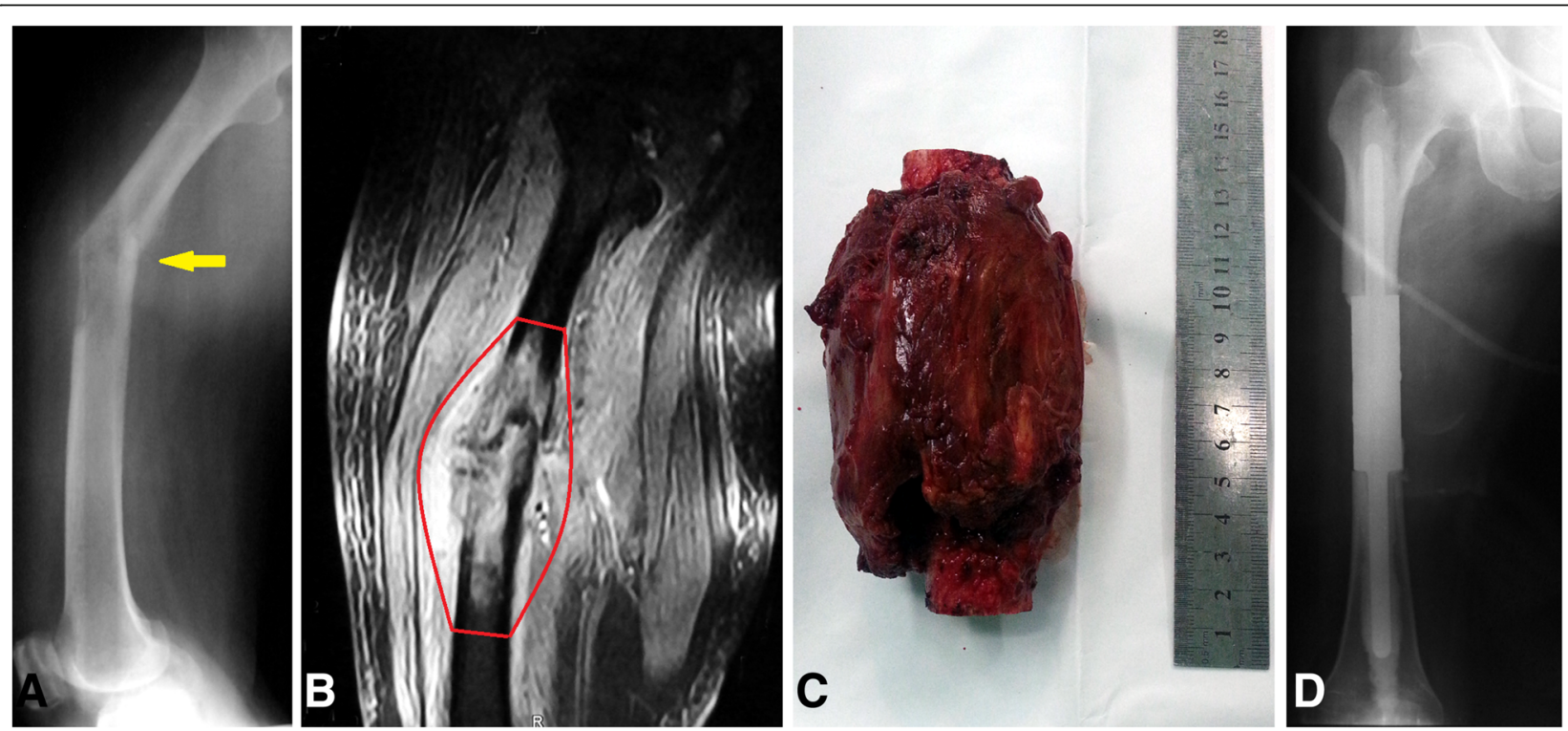

Fig. 1 All patients underwent en bloc resection of tumors, followed by reconstruction with second-generation modular intramedullary segmental prostheses characterized by a lap joint. a Radiograph of the right femur and (B) coronal magnetic resonance imaging of the upper leg of a 74year-old woman with rectal carcinoma involving the diaphysis of the femur (Patient 16). The yellow arrow in a showing the site of the femoral pathological fracture. The red line in $\mathbf{b}$ showing the surgical margin. $\mathbf{c}$ En-bloc resection of a malignant bone tumor. $\mathbf{d}$ Postoperative radiograph of the femur at 2 months after surgery, showing a stable diaphyseal construction 

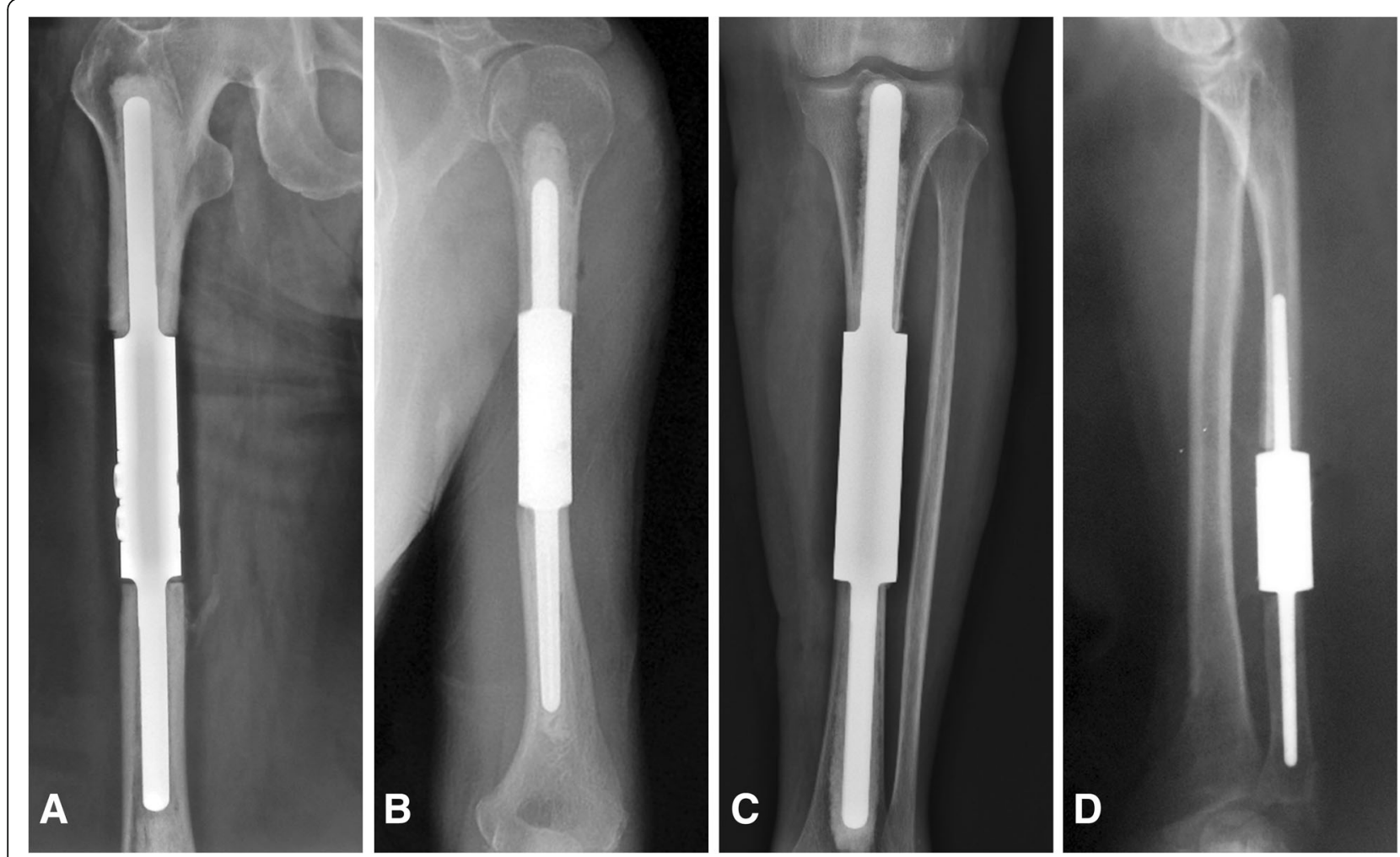

Fig. 2 In this study, modular intramedullary segmental prosthesis reconstruction was performed in all patients, which included 30 (61.2\%) femora, 13 (26.5\%) humeri, five (10.2\%) tibiae, and one (2.0\%) ulna. Radiographs showing examples of diaphyseal reconstruction of the (a) femur, $\mathbf{b}$ humerus, c tibia, and $\mathbf{d}$ ulna using modular intramedullary segmental prostheses. For these four patients, no assistant plate had been used because the remaining bone marrow cavity was long enough

therapy was undertaken as soon as possible postsurgery, the clinical effect of nerve function recovery was not obvious. Delayed incision healing occurred in three patients, including two with reconstruction in the thighs and one in the leg, for whom the incisions healed only after incisional debridement and repeated dressing replacements. No periprosthetic infections occurred in this series because of good soft tissue coverage. All patients who accepted prosthetic reconstruction of the tibia got muscle flap transposition in order to protect the prosthesis and reduce the risk of periprosthetic infection. One patient (patient 4) experienced humeral prosthesis aseptic loosening at 7 months, visible on imaging examination, without pain or other clinical symptoms. The patient refused prosthesis revision and had limited upper limb function until she died. Another patient (patient 11) experienced humeral prosthesis aseptic loosening and refused prosthesis revision as well. The difference was that this patient got aseptic loosening at 12-months post-surgery and still lived with acceptable limb function. One patient (patient 27) experienced structural complications which were found on postoperative X-ray examination. An angle of almost 13 degrees was found between the prosthetic force axis and the biological force axis. No clinical symptoms were apparent after the operation. Unfortunately, the patient died of tumor progression at 3 months post-surgery. One patient (patient 18) accepted hip dislocation at 12 months after femoral prosthetic reconstruction because of recurrent osteosarcoma in the femur. One patient (patient 45) accepted thigh amputation at 7 months after tibial prosthetic reconstruction because of Langerhans cell sarcoma recurrence in popliteal. Another patient (patient 48) accepted thigh amputation at 7 months after tibial prosthetic reconstruction because of malignant fibrous histiocytoma recurrence in the leg. The first two patients (patient 18 and 45) lived without tumor recurrence after amputation, while the third patient (patient 48) died because of tumor progression.

Although the incidence of complications in primary tumor patients $(4 / 7,57.1 \%)$ was higher than that in patients with metastatic tumors $(7 / 42,16.7 \%)(p=0.036)$, the complications seen in the former were mostly local tumor recurrence and incision complications. Aseptic loosening and mechanical complications were not common for patients with resected primary tumors, although the reconstruction length difference was statistically significant $(p=0.023)$. No statistically significant differences 

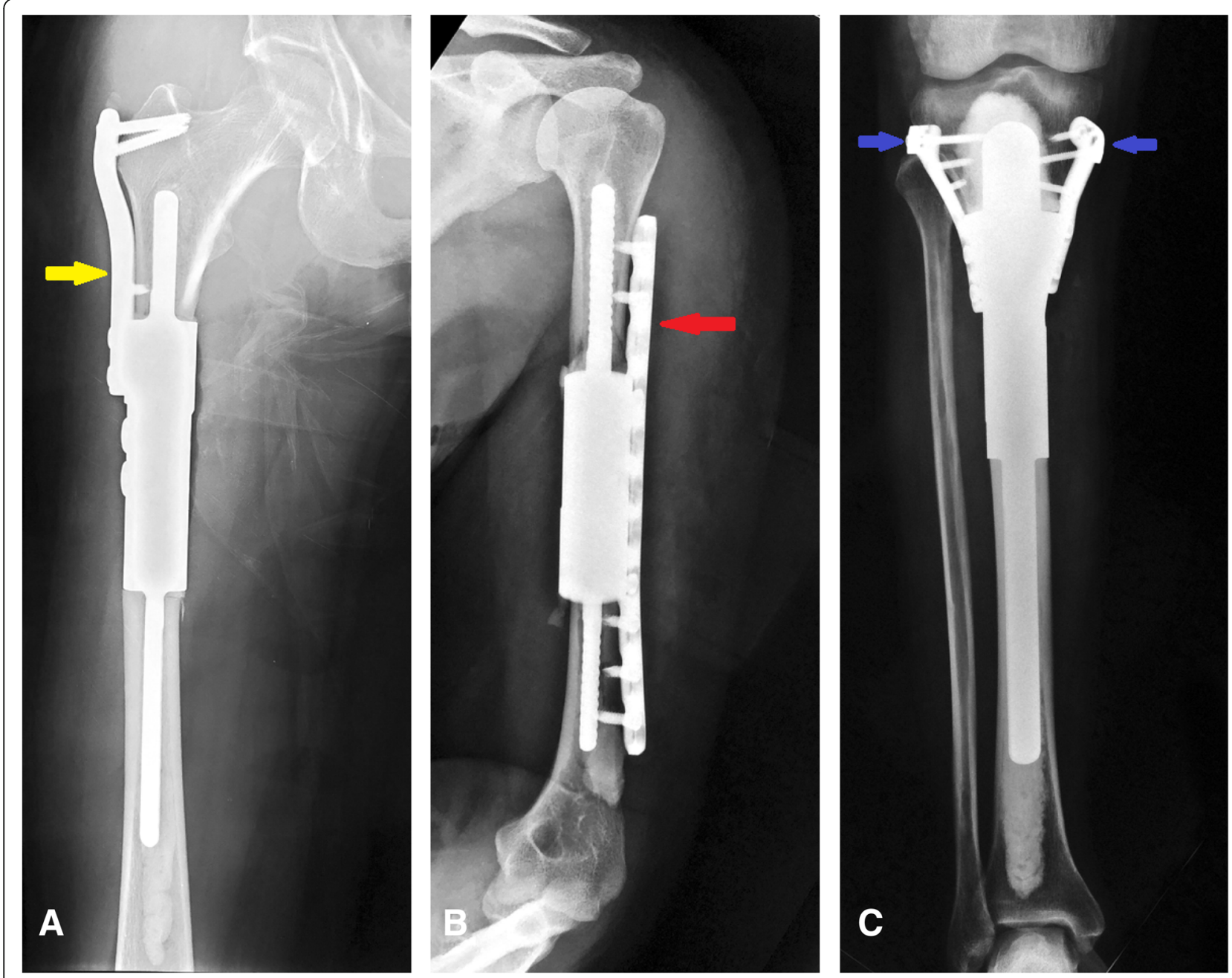

Fig. 3 All prosthesis intramedullary stems were fixed with bone cement and an assistant plate was used when the intramedullary stem was shorter than $5 \mathrm{~cm}$. Radiographs evidencing the use of assistant plates in (a) the femur and (c) tibia. The yellow arrow in a showing the unilateral assistant plate used in the proximal femur. The biomechanical analysis showed that the use of assistant plate improved the rigidity of anti-tension and anti-torsion, and diminished the risk of prosthetic loosening and dislocation. The use of an assistant plate in the humerus can effectively reduce the stress and the risk of loosening of the prosthesis. The red arrow in $\mathbf{b}$ showing a long assistant plate used in humerus. In this study, 12 patients accepted assistant plate fixation of the prothesis, including 5 for the humerus, 6 for the femur, and one for the tibia

Table 2 Cases of implant failure categorized according to criteria proposed by Henderson et al

\begin{tabular}{ll}
\hline Type of failure & Number of patients (\%) \\
\hline I (soft tissue failure) & $5(10.2 \%)$ \\
II (aseptic loosening) & $2(4.1 \%)$ \\
III (structural failure) & $1(2.0 \%)$ \\
IV (infection) & $0(0 \%)$ \\
V (tumor progression) & $3(6.1 \%)$ \\
\hline
\end{tabular}

were observed in limb function, while the mean MSTS score was 21.2 in femora, 19.6 in humeri, and 17.8 in tibiae $(p=0.134)$.

\section{Discussion}

The optimal reconstruction of diaphyseal defects after tumor resection remains controversial. Vascularized fibula autograft is considered to be the best method for early bone graft healing. However, the average weight-bearing time for reconstruction of femoral shaft defects is 13 months [21]. Allografts are considered to be the best method for the reconstruction of bone defects. However, the infection rate is $10-30 \%[5,22]$, the rate of nonunion is as high as $30-63 \%[22,23]$, and the incidence of bone graft fracture is $14-42 \%[5,24-26]$. In addition, 
postoperative radiotherapy and chemotherapy may cause the failure of biological reconstruction and postoperative complications [27]. In contrast to the above methods, the clinical outcome of segmental prosthesis reconstruction is not affected by the length of bone defect. The stable prosthesis can be obtained when the fixed length of the prosthetic stem is higher than $5 \mathrm{~cm}$ [13]. Assistant plates can be used to reinforce prosthesis stability if the length of the intramedullary stem is not more than $5 \mathrm{~cm}$. Immediate postoperative stability of the segmental prosthesis is beneficial to the recovery of limb function after operation. In this series, all patients that accepted segmental prosthesis diaphyseal reconstruction after tumor resection experienced pain relief and early limb function recovery. This research attempts to clarify the criteria that deem a patient suitable for this operation. First, patients with both diaphyseal metastases in long bones and pathological fractures should be advised to accept segmental prosthesis. Second, patients with diaphyseal metastases in long bones with high risk of fracture and poor bone condition should also consider accepting segmental prosthesis. Third, segmental prosthesis could be considered as an option in limb salvage surgery for poor prognosis patients with primary malignant tumors in the diaphysis.

Aseptic loosening is the main factor contributing to segmental prosthesis failure, reported to account for $25 \%$ in the literature [11]. Clinical studies have found that prosthesis loosening is much more common in the humerus than the femur $[9,11]$. In this series, aseptic loosening occurred in two patients with lesions in the humerus. Interestingly, no loosening (0/5) was observed when an assistant plate was used for prosthesis fixation, whereas loosening $(2 / 8)$ occurred when the prosthesis was fixed with bone cement only. Similar to compressive stress in femoral prosthesis, the tensile and torsional stresses on humeral prosthesis may be the main causes of segmental prosthesis loosening in the humerus. The use of an assistant plate in the humerus can effectively reduce the stress and the risk of loosening of the prosthesis. The incidence of segmental prosthesis loosening in this study was lower than previously reported $[10,11,17]$. The reasons for this have been analyzed and listed. First, most patients in this study had short survival time, with a median of 9 months. Second, assistant plates were used in order to reduce loosening which may be caused by the short intramedullary stem. Third, the average age of these patients was 63.3 years and most presented with multiple metastases which imply less daily activities and, consequently, lower risk of loosening. Fourth, prosthesis stem fixation with polymethyl methacrylate (PMMA) for this intercalary segmental prosthesis is advantageous because of the limited survival time and poor bone condition. Some studies have demonstrated increased postoperative function recovery in patients with cemented stems $[10,28]$.
The average function result of all 49 patients, as measured by the MSTS score, was 20.6 points, which is comparable to that reported in other studies $[10,11,17]$. Although the rehabilitation of limb function was not complete, patients experienced adequate pain relief and self-care limb functions. In particular, the short postoperative recovery time and early full weight-bearing are particularly valuable for patients with short life expectancy.

It is necessary to alert readers to be aware of the limitations of this study. Firstly, the number of patients is still small although it is the largest series among the reports owing to the fact that prosthesis reconstruction for diaphyseal defects following malignant tumor resection are rare. Without large sample statistical analysis, it is hard to make any definitive statements regarding the differences of recurrences, complications and postoperative function among different tumors and locations. Secondly, this is a multicentric retrospective study and the patients' treatments were decided by three experienced bone tumor surgeon teams respectively, consequently, the differences among surgical technologies can-not be avoided. Nevertheless consensuses of treatments had been made by these surgeon teams. Thirdly, the mean follow-up is short and additional clinical events might occur with longer follow-up. Nevertheless, 32 patients in all 49 patients were deceased in this follow-up.

\section{Conclusions}

In conclusion, segmental prostheses represent an optional method for diaphyseal defect reconstruction after bone metastasis resection. The main advantages of this approach include easy operation, early weight-bearing and acceptable incidence rate of complications. Moreover, segmental prostheses in the humerus experienced more complications than those used to treat lesions in the femur.

\section{Abbreviations}

CT: Computer tomography; ECT: Emission Computed Tomography; MR: Magnetic resonance; MSTS: Musculoskeletal Tumor Society; PMMA: Polymethyl methacrylate

\section{Acknowledgements}

Not applicable.

\begin{abstract}
Authors' contributions
$\mathrm{KZ}$ analyzed and interpreted the patient data regarding the diaphyseal defect reconstruction. $X Y$ put forward research idea and participate in result interpretation and this writing. $\mathrm{KZ}, \mathrm{XY}, \mathrm{YH}$, and $\mathrm{ZS}$ had been involved in the development of research. All authors performed the patients' treatments and MX, BW, and FW performed the patients' follow-up. All authors read and approved the final manuscript.
\end{abstract}

Funding

Not applicable.

Availability of data and materials

The datasets used and/or analysed during the current study are available from the corresponding author on reasonable request. 


\section{Ethics approval and consent to participate}

We had prior ethics approval from Institutional ethical committee of Jinan Military General Hospital (NO: 2010017) and adult patient consent or child guardian consent (under 16-year old) was obtained for this study. The research was carried out according to the principles set out in the Declaration of Helsinki 1964 and all subsequent revisions.

\section{Consent for publication}

The consent for publication of the data was obtained from all adult patients or child guardian (under 16-year old) and the relevant institutional review board had approved the study.

\section{Competing interests}

The authors declare that they have no competing interests.

\section{Author details}

'Department of Orthopedics, The 960th Hospital of the PLA Joint Logistice Support Force (previous name: General Hospital of Jinan Military Command), No. 25 Shifan Road, Jinan 250031, China. ${ }^{2}$ Department of Orthopedics, Tianjin Hospital, Tianjin, China. ${ }^{3}$ Department of Orthopedics, Union Hospital, Tongji Medical College, Huazhong University of Science and Technology, Wuhan, China.

Received: 28 September 2018 Accepted: 24 June 2019

Published online: 28 June 2019

\section{References}

1. Zekry KM, Yamamoto N, Hayashi K, Takeuchi A, Alkhooly A, Abd-Elfattah AS, Elsaid A, Ahmed AR, Tsuchiya $H$. Reconstruction of intercalary bone defect after resection of malignant bone tumor. J Orthop Surg (Hong Kong). 2019;27:2309499019832970.

2. Shammas RL, Avashia YJ, Farjat AE, Catanzano AA, Levin LS, Eward WC, Brigman BE, Erdmann D. Vascularized fibula-based Physis transfer: a followup study of longitudinal bone growth and complications. Plast Reconstr Surg Glob Open. 2017;5:e1352.

3. Houdek MT, Wagner ER, Bishop AT, Shin AY, Rose PS, Sim FH, Moran SL. Complications and long-term outcomes of free fibula reconstruction following resection of a malignant tumor in the extremities. Plast Reconstr Surg. 2017;139:510e-9e.

4. Aponte-Tinao LA, Albergo Jl, Ayerza MA, Muscolo DL, Ing FM, Farfalli GL. What are the complications of allograft reconstructions for sarcoma resection in children younger than 10 years at long-term Followup. Clin Orthop Relat Res. 2018;476:548-55.

5. Houdek MT, Rose PS, Milbrandt TA, Stans AA, Moran SL, Sim FH. Comparison of pediatric intercalary allograft reconstructions with and without a free vascularized fibula. Plast Reconstr Surg. 2018;142:1065-71.

6. Demiralp B, Ege T, Kose O, Yurttas Y, Basbozkurt M. Reconstruction of intercalary bone defects following bone tumor resection with segmental bone transport using an llizarov circular external fixator. J Orthop Sci. 2014;19:1004-11.

7. Puri A, Gulia A, Jambhekar N, Laskar S. The outcome of the treatment of diaphyseal primary bone sarcoma by resection, irradiation and re-implantation of the host bone: extracorporeal irradiation as an option for reconstruction in diaphyseal bone sarcomas. J Bone Joint Surg Br. 2012;94:982-8.

8. Xu S, Yu X, Xu M, Fu Z, Chen Y, Sun Y, Su Q. Limb function and quality of life after various reconstruction methods according to tumor location following resection of osteosarcoma in distal femur. BMC Musculoskelet Disord. 2014;15:453

9. Aldlyami E, Abudu A, Grimer R, Carter SR, Tillman RM. Endoprosthetic replacement of diaphyseal bone defects. Long-term results. Int Orthop. 2005;29:25-9.

10. Benevenia J, Kirchner R, Patterson F, Beebe K, Wirtz DC, Rivero S, Palma M, Friedrich MJ. Outcomes of a modular intercalary Endoprosthesis as treatment for segmental defects of the femur, tibia, and Humerus. Clin Orthop Relat Res. 2016:474:539-48.

11. Ruggieri P, Mavrogenis AF, Bianchi G, Sakellariou VI, Mercuri M, Papagelopoulos PJ. Outcome of the intramedullary diaphyseal segmental defect fixation system for bone tumors. J Surg Oncol. 2011;104:83-90.

12. Zhang JF, Wang F, Hu YC. Reconstruction of humeral shaft defect with an intercalary Endoprosthesis following resection of tumor. Orthop Surg. 2018;10:281-4.

13. Fuchs B, Ossendorf C, Leerapun T, Sim FH. Intercalary segmental reconstruction after bone tumor resection. Eur J Surg Oncol. 2008;34:1271-6.
14. Hu YC. Surgical technique for reconstruction of diaphyseal defect with endoprosthesis following intercalary resection in femoral shaft. Orthop Surg. 2014;6:329-31

15. Chen $Y, Y u X C, X u S F, X u M$, Song RX. Impacts of tumor location, nature and bone destruction of extremity osteosarcoma on selection of limb salvage operative procedure. Orthop Surg. 2016;8:139-49.

16. Mirels H. Metastatic disease in long bones. A proposed scoring system for diagnosing impending pathologic fractures. Clin Orthop Relat Res. 1989;249: 256-64.

17. Damron TA, Leerapun T, Hugate RR, Shives TC, Sim FH. Does the secondgeneration intercalary humeral spacer improve on the first. Clin Orthop Relat Res. 2008;466:1309-17.

18. Zhao LM, Tian DM, Wei Y, Zhang JH, Di ZL, He ZY, Hu YC. Biomechanical analysis of a novel intercalary prosthesis for humeral Diaphyseal segmental defect reconstruction. Orthop Surg. 2018;10:23-31.

19. Enneking WF, Dunham W, Gebhardt MC, Malawar M, Pritchard DJ. A system for the functional evaluation of reconstructive procedures after surgical treatment of tumors of the musculoskeletal system. Clin Orthop Relat Res. 1993;286:241-6.

20. Henderson ER, Groundland JS, Pala E, Dennis JA, Wooten R, Cheong D, Windhager R, Kotz RI, Mercuri M, Funovics PT, Hornicek FJ, Temple HT, Ruggieri $P$, Letson GD. Failure mode classification for tumor endoprostheses: retrospective review of five institutions and a literature review. J Bone Joint Surg Am. 2011;93:418-29.

21. Campanacci DA, Totti F, Puccini S, Beltrami G, Scoccianti G, Delcroix L, Innocenti M, Capanna R. Intercalary reconstruction of femur after tumour resection: is a vascularized fibular autograft plus allograft a long-lasting solution. Bone Joint J. 2018;100-B:378-86.

22. Donati D, Capanna R, Campanacci D, Del Ben M, Ercolani C, Masetti C, Taminiau A, Exner GU, Dubousset JF, Paitout D. The use of massive bone allografts for intercalary reconstruction and arthrodeses after tumor resection. A multicentric European study. Chir Organi Mov. 1993;78:81-94.

23. Ortiz-Cruz E, Gebhardt MC, Jennings LC, Springfield DS, Mankin HJ. The results of transplantation of intercalary allografts after resection of tumors. A long-term follow-up study. J Bone Joint Surg Am. 1997;79:97-106.

24. Mankin HJ, Gebhardt MC, Jennings LC, Springfield DS, Tomford WW. Longterm results of allograft replacement in the management of bone tumors. Clin Orthop Relat Res. 1996;324:86-97.

25. Thompson RC, Garg A, Clohisy DR, Cheng EY. Fractures in large-segment allografts. Clin Orthop Relat Res. 2000;370:227-35.

26. Aponte-Tinao LA, Ayerza MA, Muscolo DL, Farfalli GL. Should fractures in massive intercalary bone allografts of the lower limb be treated with ORIF or with a new allograft. Clin Orthop Relat Res. 2015;473:805-11.

27. Hornicek FJ, Gebhardt MC, Tomford WW, Sorger Jl, Zavatta M, Menzner JP, Mankin HJ. Factors affecting nonunion of the allograft-host junction. Clin Orthop Relat Res. 2001;382:87-98.

28. Zhang C, Hu J, Zhu K, Cai T, Ma X. Survival, complications and functional outcomes of cemented megaprostheses for high-grade osteosarcoma around the knee. Int Orthop. 2018;42:927-38.

\section{Publisher's Note}

Springer Nature remains neutral with regard to jurisdictional claims in published maps and institutional affiliations.

Ready to submit your research? Choose BMC and benefit from:

- fast, convenient online submission

- thorough peer review by experienced researchers in your field

- rapid publication on acceptance

- support for research data, including large and complex data types

- gold Open Access which fosters wider collaboration and increased citations

- maximum visibility for your research: over $100 \mathrm{M}$ website views per year

At $\mathrm{BMC}$, research is always in progress.

Learn more biomedcentral.com/submissions 